\title{
Designing the half-masks of filter respirators for workers of mining enterprises
}

\author{
Vasyl Holinko ${ }^{1 *}$, Ivan Cheberiachko ${ }^{1}$, Hennadii Symanovych ${ }^{1}$, and Jerzy $\mathrm{Kicki}^{2}$ \\ ${ }^{1}$ Dnipro University of Technology, Department of Labour Protection and Civil Safety, \\ 19 Yavornytskoho, 49005 Dnipro, Ukraine \\ ${ }^{2}$ Mineral and Energy Economy Research Institute of the Polish Academy of Sciences, Division of \\ Mineral Resource Acquisition, 7 Wybickiego St., 31-261 Krakow, Poland
}

\begin{abstract}
The purpose of paper is to develop an algorithm for designing the half-masks of air-purifying respirators and assessment of their safety factor of insulation. To create a 3D model of a head, two-parameter NIOSH tables (National Institute for Occupational Safety and Health) were used. The model drawings were made with the use of Solid works software package. Differential geometrical method based on applying the moving Frénet trihedral was used to design half-masks. Two designs of the respirator half-mask were developed based on the averaged length and width of face (Modification 1), and length of face and lips (Modification 2 ). As a result of modeling test, the area and perimeter of the mask contact line have been defined. The safety factor of half-mask insulation was calculated theoretically. It has been established that the safety factor of Modification 1 half-mask is 2.5 times higher.
\end{abstract}

\section{Introduction}

Elastomeric half-masks are essential part of reusable air-purifying respirators. A reliable face fit, comfort and ability to communicate depend on their design [1]. Numerous research studies [2,3] on defining the efficiency of respirators in the conditions of mining enterprises have shown that provided the proper choice of a filter, the overall efficiency of respiratory protective equipment (RPE) is defined by leakage of unfiltered air through gaps between the facepiece of a half-mask (a respirator) and the face. This is the main cause of the inhaled air impurities. Appearance of gaps depends on many factors (anthropometry of the face, the work performed, headband and obturator design, and others). At the same time, their dimensions are non-constant variables. As a result, the safety factor (SF) can alter by tens of times within minutes [1]. That is why the research on determining the main mechanisms of designing elastomeric half-masks is of relevance.

Reliable insulation of respiratory organs by half-masks is inherently related to anthropometric measurements of faces. The nasal bridge area is one of the most problematic areas where gaps along the contact line are recorded most frequently [5]. About $84 \%$ of gaps were found right in this area (near the nose and cheeks). Moreover, the worst results while testing insulating capability of RPEs are recorded for being used while

\footnotetext{
*Corresponding author: golinkongu@gmail.com
} 
talking (changing facial expression). Most experts regard the following as solution to the problem: detailed studies on anthropometric characteristics of the face, which involve either defining dimensions which influence insulation properties (IP) the most or calculating universal "components" which consider all the measured facial parameters.

Thus, there arises a task of studying the influence of anthropometric characteristics of the face on the design of an elastomeric half-mask frame, which would provide high levels of its insulation properties.

The purpose of the work is to develop an algorithm of designing an elastomeric halfmask with fine insulation properties for workers of mining enterprises.

To solve the set task, it is necessary:

- to mark measurement points on workers' faces;

- to design a 3D model of elastomeric half-masks;

- to calculate the area of the contact of an obturator with the face;

- to define theoretically the safety factor of insulation of the designed half-masks.

\section{Presentation of the main material}

In order to deliver on a primary target, we used the data of the research by well-known American scientists Benson, S., Landsitttel, D., Chen, W., Zhuang, Z., Du, L., Yu, D., Wang, L., Viscusi, D., Shaffer, who considered the following facial measurements to be the most important: the length and width of the face, the length of the nose and others which are given in Table 1.

Table 1. Abbreviations and description of facial measurements.

\begin{tabular}{|l|l|l|}
\hline $\begin{array}{c}\text { Abbreviations } \\
\text { according to the } \\
\text { American standards }\end{array}$ & Facial measurements & \multicolumn{1}{|c|}{ Description of facial measurements } \\
\hline 1. BIZBDTH & Face width & $\begin{array}{l}\text { The greatest horizontal breadth of the face } \\
\text { between the zygomatic arches }\end{array}$ \\
\hline 2. BIGBRH & $\begin{array}{l}\text { Face width according } \\
\text { to the gonial angle }\end{array}$ & $\begin{array}{l}\text { Straight-line distance between the right and } \\
\text { left gonion landmarks at the corner of the jaw }\end{array}$ \\
\hline 3. NOSEBRTH & Nose breadth & $\begin{array}{l}\text { Distance between the right and left landmarks } \\
\text { on the alae of the nose }\end{array}$ \\
\hline 4. LIPLGTHH & Lip length & $\begin{array}{l}\text { Distance between the right and left cheilion } \\
\text { landmarks at the corners of the mouth }\end{array}$ \\
\hline 5. MENSELLH & Face length & $\begin{array}{l}\text { Distance between the menton and sellion } \\
\text { landmarks }\end{array}$ \\
\hline 6. SBNSSELH & Nose length & $\begin{array}{l}\text { Distance between the sellion and subnasale } \\
\text { landmarks of the nose }\end{array}$ \\
\hline 7. NOSEPRH & Nose height & $\begin{array}{l}\text { Distance between the pronasale and subnasale } \\
\text { landmarks of the nose }\end{array}$ \\
\hline
\end{tabular}

According to the recommendations, the specified dimensions can be measured with the help of calipers and a tape line or 3D scanning (Fig. 1). Work [4] gives measurements of over 400 men and women, representing the staff and students of the Mining University (Dnipro). The range of the face length of the tested individuals made from 98.5 to $143.2 \mathrm{~mm}$, the face width was from 131.3 to $164.9 \mathrm{~mm}$. The results are given in Table 2; they became the basis for creating a model of a human head. 


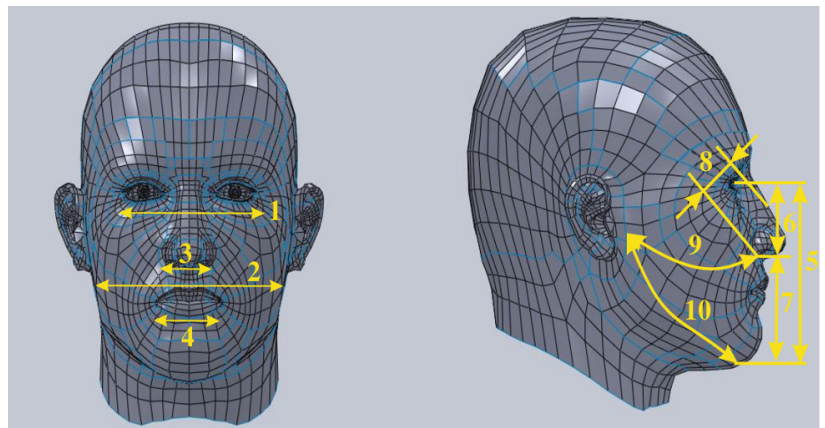

Fig. 1. Facial measurements which were taken from the volunteers.

Table 2. Results of average measurements of face dimensions, $\mathrm{mm}$.

\begin{tabular}{|l|c|c|c|}
\hline \multicolumn{1}{|c|}{ Size } & Men (320) & Women (80) & Total (400) \\
\hline 1. BIZBDTH & $144.3 \pm 8.9$ & $135.3 \pm 6.0$ & $144.5 \pm 8.9$ \\
\hline 2. BIGBRH & $130.2 \pm 9.1$ & $121.1 \pm 9.1$ & $128.4 \pm 10.1$ \\
\hline 3. NOSEBRTH & $32.7 \pm 1.9$ & $29.6 \pm 3.3$ & $32.0 \pm 3.6$ \\
\hline 4. LIPLGTHH & $51.4 \pm 3.7$ & $45.0 \pm 3.7$ & $48.7 \pm 4.8$ \\
\hline 5. MENSELLH & $121.1 \pm 8.4$ & $115.2 \pm 5.8$ & $119.8 \pm 7.8$ \\
\hline 6. SBNSSELH & $49.3 \pm 4.5$ & $43.2 \pm 3.0$ & $47.7 \pm 5.0$ \\
\hline 7. NOSEPRH & $24.1 \pm 2.7$ & $22.4 \pm 2.2$ & $23.9 \pm 2.6$ \\
\hline
\end{tabular}

There are two approaches to defining key landmarks according to which a contour of an elastomeric half-mask can be obtained. The first one is based on the data by the National Institute for Occupational Safety and Health of the USA (NIOSH). It states that measurements of the face length and lip length are the most essential for designing and testing half-masks. However, the analysis of the published research studies on evaluation of the influence of facial parameters on insulation properties of respiratory protective equipment showed that there are no distinct parameters which are the most influencing (Table 3). That is why the other approach proposed by Zhuang Z. is based on integrated factors - the so-called components PC1 and PC2. Almost all face sizes are found in them.

To calculate a component, the following formulas are proposed [11]:

PC1 (the first component $)=0.343264 \cdot($ head width over the forehead $)+0.426498 \cdot($ face width $)+0.372717$ (face width by gonion landmarks) $+0.329648 \cdot($ face length $)+$ $0.363474 \cdot($ distance between the eyebrows) $+0.372241 \cdot($ head width $)+0.113578 \cdot($ nose height $)+0.301125 \cdot($ nose width near the mouth $)+0.202311 \cdot($ nose bridge width $)+$ $0.193650 \cdot$ (nose length).

PC2 (the second component) $=-0.152951 \cdot($ head width over the forehead) $0.039087 \cdot$ (face width) -0.093279 (face width by gonion landmarks or face depth) + $0.359799 \cdot($ face length) $-0.173099 \cdot($ distance between the eyebrows $)+0.013306 \cdot($ head width $)+0.551842 \cdot($ nose height $)-0.210833 \cdot($ nose width near the mouth $)-0.341235 \cdot$ (nose bridge width $)+0.584261 \cdot($ nose length) .

To create a head, let us apply a polygonal model which is specified by a set of threedimensional coordinates of the key points, which are grouped in horizontal intersection. The three-dimensional configuration of the model is made using a manikin head which is marked with vertices, bonds and bounds. Marking $d=\left(d_{1}, d_{2}, \ldots, d_{n}\right)$ involves a set of vectors $d_{i}=\left(d_{1}^{i}, d_{2}^{i}, \ldots, d_{n}^{i}\right)$ whose elements are indexes of the model vertices. The vector defines a polygonal line which describes one distinctive feature of the face, the contour of the nose, lips or the face in general (Fig. 2). The line sizes are set with the help of 
anthropometric landmarks defined on the face. The lines make parabolic spline which continuously sets the intersection form (Fig. 2). Every spline is proportionally divided by subsidiary points in order to create an equal number of plots at every horizontal intersection. The subsidiary points are interconnected creating structured quadrilateral grid cells. To get a smoother form, every quadrangle of the grid can be depicted as Coons bicubic surface with predefined steps of division. The surface obtained is smoothed.

Table 3. Research analysis of interrelationship between facial parameters and insulating properties of half-masks.

\begin{tabular}{|c|c|c|c|}
\hline $\begin{array}{l}\text { Analyzed } \\
\text { publications }\end{array}$ & Respirator models & $\begin{array}{l}\text { The number of } \\
\text { participants }\end{array}$ & Conclusions \\
\hline$[7]$ & $\begin{array}{l}\text { U.S. Safety Series } 200 \\
\text { half-mask }\end{array}$ & $\begin{array}{l}39 \text { males } \\
34 \text { females }\end{array}$ & $\begin{array}{l}\text { Nose length, face length and lip } \\
\text { length }\end{array}$ \\
\hline [8] & $\begin{array}{l}\text { U.S. Safety Series } 200 \\
\text { half-mask }\end{array}$ & 38 males & $\begin{array}{l}\text { Nose length, face length and lip } \\
\text { length }\end{array}$ \\
\hline [9] & AO 5-Star Series & 30 females & $\begin{array}{l}\text { Face length, face width and } 5 \text { other } \\
\text { dimensions }\end{array}$ \\
\hline [10] & North 770 Series & 20 males & $\begin{array}{l}\text { Respirator IPs weakly depended on } \\
\text { facial dimensions related to racial } \\
\text { and ethnic group; IPs were } \\
\text { influenced by nose length and } \\
\text { protrusion }\end{array}$ \\
\hline [11] & Survivair Series 2000 & 21 females & Face width and nose protrusion \\
\hline [12] & $\begin{array}{l}\text { MSA Advantage half- } \\
\text { mask }\end{array}$ & 186 subjects & $\begin{array}{l}\text { For } 28 \text { respirator models/sizes out of } \\
33 \text {, IPs were significantly influenced } \\
\text { by } 1 \text { to } 6 \text { facial dimensions: face } \\
\text { width ( } 11 \text { cases), nose protrusion } \\
\text { and face width ( } 8 \text { cases), face length } \\
\text { ( } 5 \text { cases) }\end{array}$ \\
\hline
\end{tabular}

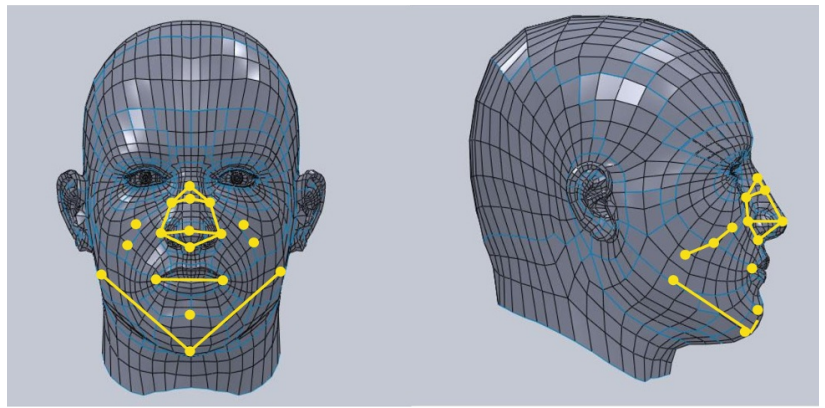

Fig. 2. Modelling with the frame defined by curved lines.

For designing half-masks let us use the differential geometrical method based on applying the moving Frénet trihedral (FT) of a three-dimensional curve [12]. Let there be defined a FT at the point A of a segment of the curve which consists of regular points; the FT has $t, n, b$ which are vectors of the tangent line, normal and binormal, correspondingly. We will consider formation of linear surface between the unitary vector and the $i$-th normal, which passes through the point A of the defined curve (Fig. 3).

The coordinate position of the unitary vector is defined by the angles: $\alpha=I \wedge I_{t n}$; $\beta=I_{t n} \wedge t$, where $I_{t n}$ is the orthogonal projection of unitary vector I on the tangential plane $(t, \mathrm{n})$ of the curve at the point A. As known, the FT position is defined by the natural 
parameter s of the curved line. That is why we assume that each of the angles $\alpha, \beta$ is a function of the parameter s. In this case we obtain an equation:

$$
I=(\tau \cos \beta+\pi \sin \beta) \cos \alpha+\bar{b} \sin \alpha .
$$

It is known that the condition of coplanarity of vectors is a necessary and sufficient condition for the linear surface to be developed.

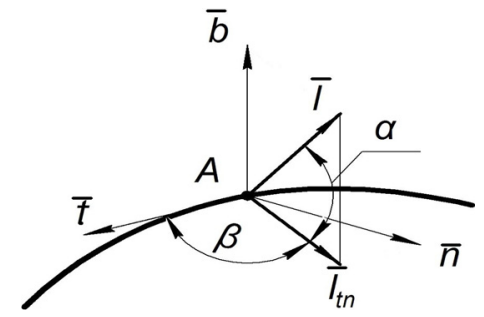

Fig. 3. Position of the Ith generator of linear surface.

Two modifications of elastomeric half-mask design were created [13]. For the first modification, they considered face width, nose breadth, distance from the nose bridge to the menton, and the face width by the gonion landmarks at the corner of the jaw. As for the other, a distance from the nose bridge to the menton, the nose breadth and lip length were taken into account. Based on the obtained data and averaged measurement results given in Table 2, positioning of key landmarks on the face for designing an obturation line was proposed (Fig. 4).
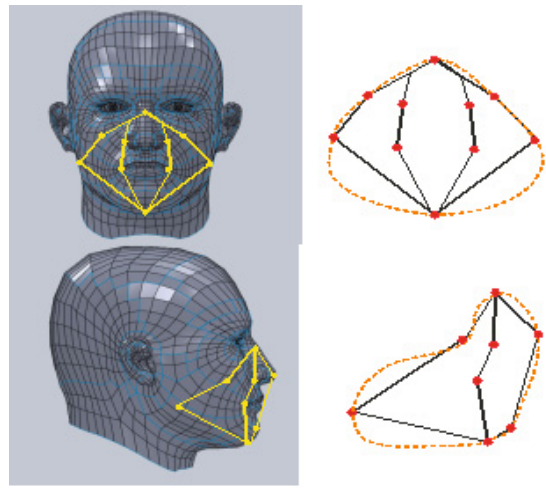

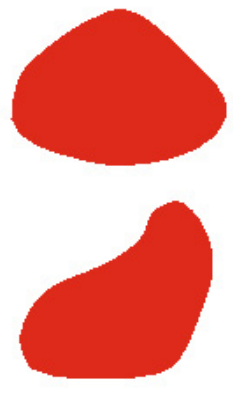

Modification 1

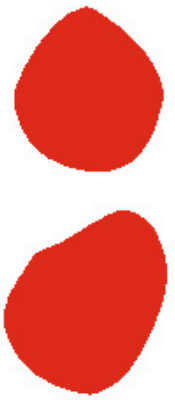

Modification 2

Fig. 4. Designed half-mask contours.

The nose breadth and distance from the nose bridge to the menton are common for both modifications. Regarding the difference, it concerns the choice of either the face width or lip length. Thus, the obturator contour is narrow in the upper part of the face and widens downwards in order to cover the cheeks. In our opinion, Modification 1 decreases the influence of facial expressions when talking or turning the head. In Modification 2, the contour line focuses on around the nose and mouth; it requires far lesser material. 3D models of half-masks based on the designed contour lines are given in Fig. 5. Further actions involved attaching the half-mask to the head model in order to define the area of contact along the obturation line (Fig. 6). To calculate the total contact area of the halfmask and the face, the head model was covered with special square cells.

The contact area between the head and half-mask has the form of a non-regular circle restricted by internal and external boundary curves (Fig. 7). Let us consider he surface of 
the contact area to be symmetrical, because both sides of the head and half-mask are symmetrical. Possible asymmetry at a first approximation was not considered. Certain contact plots were fitted by hand because of uncertainties of 3D half-mask image design. The nose bridge area, which is protruded, is the most challenging. The results of calculating the obturation line area are given in Table 4.
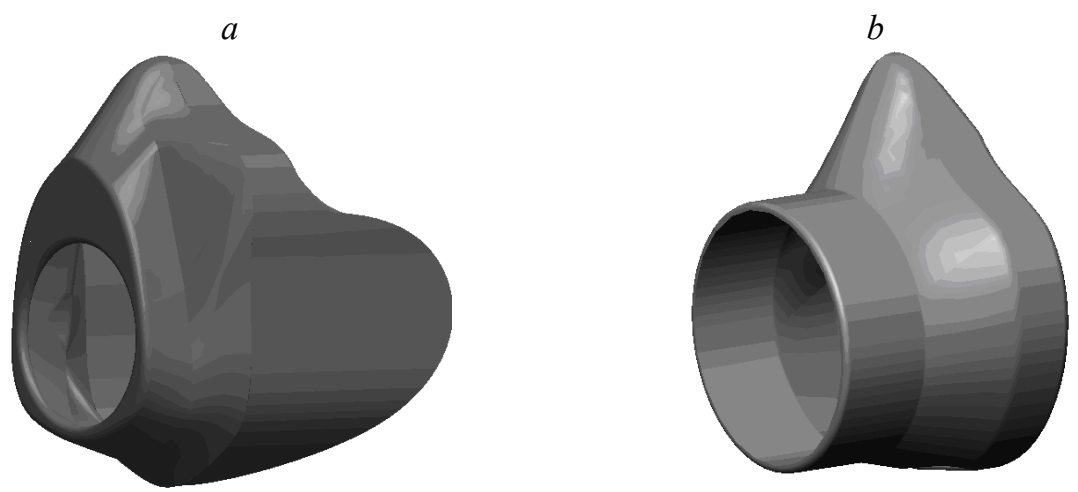

Fig. 5. 3D models of elastomeric half-masks for Modification 1 (a) and Modification 2 (b).
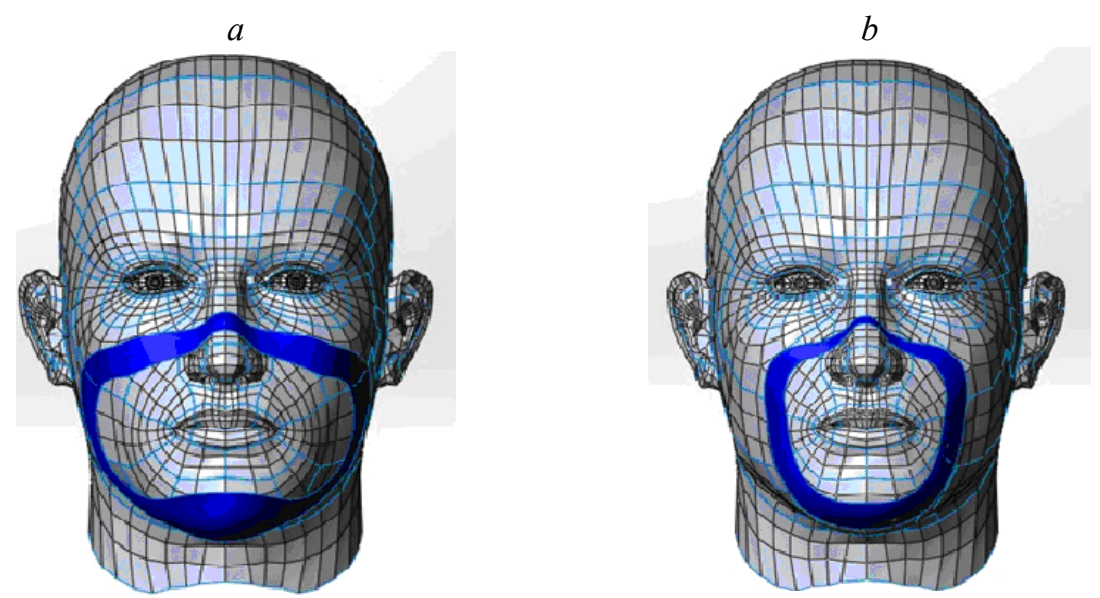

Fig. 6. View of attaching the 3D models of half-mask to the head model for Modification 1 (a) and Modification 2 (b).
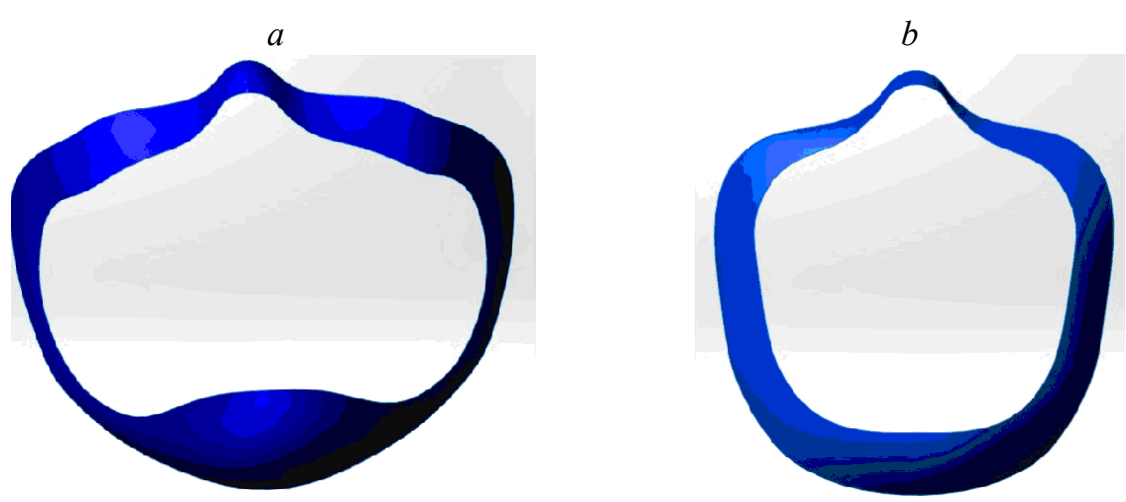

Fig. 7. View of the obturation line for Modification 1 (a) and Modification 2 (b). 
Table 4. Results of calculating the area of the obturation line.

\begin{tabular}{|c|c|c|c|c|c|c|}
\hline \multirow{3}{*}{ Modification } & \multicolumn{4}{|c|}{ Area of the obturation according to facial } & \multirow{2}{*}{$\begin{array}{c}\text { Total contact } \\
\text { areas, } \mathrm{cm}^{2}\end{array}$} & $\begin{array}{c}\text { Mean width of } \\
\text { area } \mathrm{cm}^{2}\end{array}$ \\
\cline { 2 - 5 } & $\begin{array}{c}\text { nose } \\
\text { bridge }\end{array}$ & $\begin{array}{c}\text { right } \\
\text { cheek }\end{array}$ & $\begin{array}{c}\text { left } \\
\text { cheek }\end{array}$ & mentum & & \\
\hline 1 & 0.08 & 0.212 & 0.208 & 0.33 & 0.84 & 0.9 \\
\hline 2 & 0.06 & 0.132 & 0.128 & 0.16 & 0.48 & 0.6 \\
\hline
\end{tabular}

For theoretical calculation of insulation properties of the designed half-masks, let us calculate the insulation factor of the half-mask by the formula [14]

$$
K_{i}=\frac{1+K_{p}}{\eta_{t}},
$$

where $K_{p}=Q_{0} / Q_{a}$ is the airflow rate coefficient; $Q_{0}$ is the total airflow rate through the respirator, $\mathrm{dm}^{3} / \mathrm{min} ; Q_{a}$ is the airflow rate through the gaps along the contact line; $\eta_{t}$ is the coefficient of penetration through the leakage along the contact line.

Let us compare the inflow of aerosol particles due to possible unevenness along the obturation line to the aspiration of aerosol into a gap. In this case, let us use the formula proposed by Hinds [15]:

$$
\begin{gathered}
\eta_{t}=1-5.5 k_{2}^{\frac{2}{3}}+3.77 k_{2} \text { with } k_{2}<0.009 \\
\eta_{t}=0.819 \exp \left(-11.5 k_{2}\right)+0.0975 \exp \left(-70.1 k_{2}\right) \text { with } k_{2}>0.009,
\end{gathered}
$$

where $k_{2}=D L_{1} / Q_{a} ; L_{1}$ is the width of the sealer or the length of the tube, m; $D$ is the diffusion coefficient.

To define leakages along the contact line, let us apply the theory of contact interaction of elastoplastic surfaces. If we accept that gaps formed between a person's face and the obturation line make capillary tubes of size $\mathrm{d}$, the airflow rate through every centimeter of the sealing contour will equal [16]:

$$
Q_{a}=n \frac{d^{5}}{S} \frac{\Delta P}{\mu}, \mathrm{m}^{3} / \mathrm{s},
$$

where $n$ is the number of tubes in one centimeter; $\Delta P$ is pressure drop across the respirator, $\mathrm{Pa} ; \mu$ is the dynamic coefficient of air viscosity, $\mathrm{Pa} \cdot \mathrm{s} ; S$ is the area of the obturation line, $\mathrm{m}^{2}$.

$$
d=-\frac{k\left(\Delta p-\Delta p_{1}\right)}{4}
$$

where $\Delta p$ is the pressure drop across the respirator worn by a test person, $\mathrm{Pa} ; \Delta p_{1}$ is the pressure drop across a half-mask tightly sealed, $\mathrm{Pa} ; k$ is a coefficient of proportionality, $\mathrm{m} / \mathrm{Pa}$.

The calculation results are summarized in Table 5.

Table 5. Calculation data on half-masks.

\begin{tabular}{|c|c|c|c|c|}
\hline Modification & $\begin{array}{c}\text { Allowed airflow rate } \\
\text { through the obturation } \\
\text { line, } \mathrm{dm}^{3} / \mathrm{min}\end{array}$ & $\begin{array}{c}\text { Coefficient of } \\
\text { aspiration }\end{array}$ & $\begin{array}{c}\text { Coefficient of } \\
\text { airflow rate }\end{array}$ & $\begin{array}{c}\text { Safety factor of } \\
\text { insulation }\end{array}$ \\
\hline 1 & 0.8 & 0.71 & 110 & 154.9 \\
\hline 2 & 1.7 & 0.92 & 54 & 60.5 \\
\hline
\end{tabular}




\section{Discussion}

As a consequence of calculations, we obtained expected results regarding the value of the safety factor of insulation of half-masks. Understandably, probability of formation of additional ways of inflow of aerosol particles decreases with increasing area of the obturation line. However, it does not mean that Modification 2 should be rejected. It is believed that it will provide for tight sealing when being used by workers with small face dimensions [17]. Similar half-mask designs are used by well-known manufacturers (for example, Advantage 200 Respirator). At least this premise requires further testing. Another reason for further development in this regard is that Modification 2 showed fairly good results. If the safety factor of insulation is defined according to certain facial areas, it is found that in the area of the nose bridge the factor is almost equal for both modifications. The lowest result is recorded where the obturator width is narrow. Let us note that the designing of both half-masks through the vertical plane of the face was done according to almost similar landmarks. Considering the fact that occurrence of inflow is the greatest exactly in the upper part of a half-mask, the specimens designed are under the same conditions. To deal with this disadvantage further research is required on both peculiar design and elastomeric materials capable of conforming to the contour of the face. Nevertheless, experimental studies indicate that talking or turning the head, when facial expressions change, causes increasing subsequent gaps exactly in the area of the cheeks and chin [5]. It is obvious that in these instances while using respirators, Modification 1 is preferable. Thus, we note the need for further research on defining obturator design for different face types and conducting field observations of half-masks produced according the given approach.

\section{Conclusions}

Based on the analysis of open access publications, the major anthropometric measurements of faces were defined following which two modifications of obturators of half-mask respirators have been designed. Modification 1 is based on the mean data on the face width and length, whereas Modification 2 relies on the length of the face and lips. As a result of testing through modelling with appropriate software, the area and perimeter of the obturation line were defined. This allowed evaluating the half-mask safety factor of insulation theoretically. Consequently, Modification 1 featured the safety factor which is 2.5 times higher. However, the width of the obturation line in the nose bridge area is almost equal for both modifications, which indicates the need for further development of half-mask designs to provide better protective properties of respirators.

This work was conducted within the projects "Improvement of the effectiveness of personal protective equipment for workers in mining enterprises" (State registration No. 0114U000620) and "Development of universal means of individual protection of prolonged action of dual purpose" (State registration No. 0117U000376).

\section{References}

1. Kirillov, V.F., Bunchev, A.A., \& Chirkin, A.V. (2013). On means of individual protection of respiratory organs of the workers (literature review). Labour Medicine and Industrial Ecology, (4), 25-31.

2. Bondarenko, V., Kovalevs'ka, I., \& Fomychov, V. (2012). Features of carrying out experiment using finite-element method at multivariate calculation of "mine massif - combined support" system. Geomechanical Processes During Underground Mining - Proceedings of the School of 
Underground Mining, 7-14. http://dx.doi.org/10.1201/b13157-3

3. Kovalevska, I., Symanovych, G., \& Fomychov, V. (2013). Research of stress-strain state of cracked coal-containing massif near-the-working area using finite elements technique. Annual Scientific-Technical Collection - Mining of Mineral Deposits 2013, 159-163. http://dx.doi.org/10.1201/b16354-28

4. Kovacs, L., Immermann, A., \& Brockmann, G. (2006). Three-dimensional recording of the human face with a 3D laser scanner. J. Plast. Reconstr. Aesthet. Surg., (59), 1193-1202.

5. Golinko, V., Cheberiachko, S., Naumov, M., \& Cheberiachko, Y. (2014). Comparative studies of protective effectiveness of filter respirators in laboratory and production conditions. Naukovyi Visnyk Natsionalnoho Hirnychoho Universytetu, (1), 99-105.

6. Oestenstad, R.K., \& Perkins, L.L. (1992). An assessment of critical anthropometric dimensions for predicting the fit of a halfmask respirator. American Industrial Hygiene Association Journal, 53(6), 639-644.

7. Oestenstad, R.K., Elliot, L.J., \& Beasley, T.M. (2007). The effect of gender and respirator brand on the association of respirator fit with facial dimensions. Journal of Occupational and Environmental Hygiene, (4), 923-930.

8. Brazile, W.J., Buchan, R.M., Sandfort, D.R., Melvin, W., Johnson, J.A., \& Charney, M. (1998). Respirator fit and facial dimensions of two minority groups. Appl Occup Environ Hyg., (13), 233237.

9. Han, D.H., \& Choi, K.L. (2003). Facial dimensions and predictors of fit for half-mask respirators in Koreans. AIHA J., (64), 815-822.

10. Zhuang, Z., Bradtmiller, B., \& Shaffer, R.E. (2007). New respirator fit test panels representing the current U.S. civilian work force. J Occup Environ Hyg., (4), 647-659.

11. Zhuang, Z., Landsittel, D., Benson, S., Roberge, R., \& Shaffer, R. (2010). Facial anthropometric differences among gender, ethnicity, and age groups. Ann Occup Hyg., (54), 391-402.

12. Niteiskii, A.S. (2013). Designing developable surface by the method of moving Frénet trihedral. Omsk Scientific Bulletin, 2(120), 151-153.

13. Gutierrez, A1.M., Galang, M.D., Seva, R.R., Lu, M.C., \& Ty, D.R.S. (2014). Designing an improved respirator for automotive painters. International Journal of Industrial Ergonomics, (44), 131-139.

14. Golinko, V., Cheberiachko, S., Cheberiachko, Y., \& Radchuk, D. (2015). Increasing the protective effectiveness of elastomeric filter respirators. Vostochno-Yevropeyskiy zhurnal peredovykh tekhnologiy, 2(6), 60-64.

15. Hinds, W.C. (1987). Performance of dust respirators with facial seal leaks expérimental. American Industrial Hygiene Association Journal, (48), 836-841.

16. Gurevich, D.F. (1969). Calculation and design of pipe fittings. Leningrad: Mashinostroenie.

17. Holinko, V., Cheberiachko, S., Yavorska, O., \& Radchuk, D. (2016). Study of protective properties of half-masks respirators used by miners. Mining of Mineral Deposits, 10(4), 29-36. https://doi.org/10.15407/mining10.04.029 